\title{
TITLE VERY HIGH RESOLUTION SATURATION SPECTROSQCPY OF LUTETIUM ISOTOPES VIA CW SINGLE-FREQUENCY LASER RESONANCE IONIZATION MASS SPECTROMETRY
}

\section{ILS-III Conference Proceedings}

\section{DISC I.AIMER}

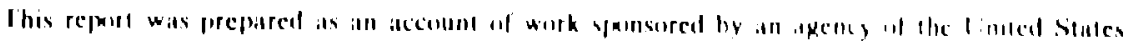

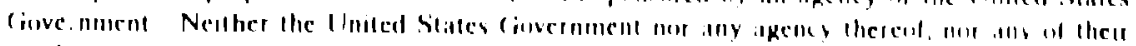

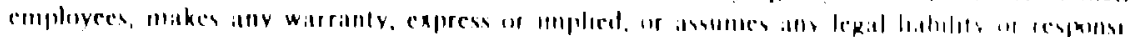

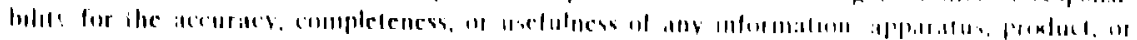

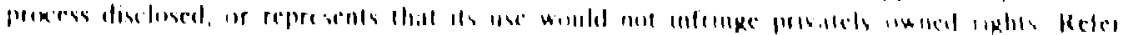

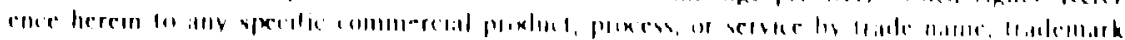

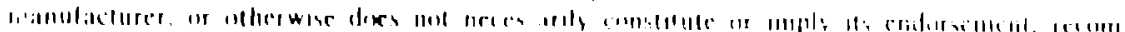

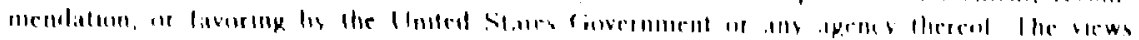

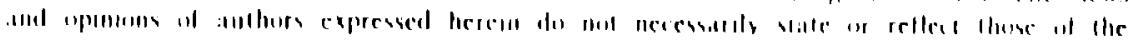

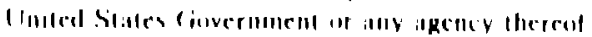




\title{
VERY HIGH RESOLUTION SATURATION SPECTROSCOPY OF LUTETIUM ISOTOPES VIA CW SINGLE-FREQUENCY LASER RESONANCE IONIZATION MASS SPECTROMETRY
}

\author{
B. L. Fearey, ${ }^{1}$ D. C. Parent, ${ }^{21}$ R. A. Keller, ${ }^{2}$ and C. M. Miller ${ }^{1}$ \\ ${ }^{1}$ lsotope and Nuclear Chemistry Group INC-7 \\ ${ }^{2}$ Chemical and Laser Sciences Group CLS-2 \\ Los Alamos National Laboratory, Los Alamos, NM 87545
}

\begin{abstract}
In this paper, we discuss the use of Resonance lonization Mass Spectrometry (RIMS) to perform isotopically selective saturation spectroscopy of lutetium isotopes. Utilizing this technique, it is shown that accurate mcasurements of the relative frequencies of hyper6ne (HF) components for differert isotopes easily can be made without the need for an isotopically enriched sample. The precision with which the HF aplitting constants can be determined is estimaled to be $\sim 5$ times greater than in previous rvork.
\end{abstract}

\section{INTRODUCTION}

Considerable interest in the technique of RIMS has developed over recent years due to: 1) the selective manner in which isobaric intes 'erences are discriminated against, 1.2 and 2) the large dynamic range available for measuring isotopic ratios. ${ }^{3}$ Earlier work ${ }^{3}$ has demonstraled the ability to measure lutetium isotopic ratios down to the $0.4 \mathrm{ppm}$ level on very amall samples ( $60 \mathrm{ng})$. In this previous work, the isotope ratio dynamic range wa basically limited by low signal. Recently however, we have demonstrated that using a second, high-power, non-resonant laer for the ionisation step can dramatically increase ionisation efficiency. ${ }^{4,6}$ Here, the mase spectrometer resolution witimately limits the dynamic range. In order to significantly increase the dynamic range oven further, it may bocome necessary to perform sotopically selective resonance ionization. In the present work, Doppler-free saturation opectroscopy vie RIMS is utilised for this goal, i.e., to obtain precise determination of the various HF components for the lutetium isotopes.

\section{EXPERIMENTAL SECTION}

Briety, an ultraviolet $\mathrm{Ar}^{+}$laser pumped ring dyo laser operating with Stilbene 3 ( $65 \mathrm{~mW}$ ) wa tuned to the one-photion transition of lutetium $\left(5 \mathrm{~d} 6 \mathrm{~s}_{0} \mathrm{p}^{2} \mathrm{D}^{\circ}{ }_{3 / 2}-5 \mathrm{~d} \mathrm{~s}^{2}\right.$ $\left.{ }^{2} \mathrm{D}_{3 / 2}\right)$ at $\sim 22125 \mathrm{rm}^{-1}(\sim 452 \mathrm{~nm})$. To increase the ionisation efficiency, ${ }_{1}^{4,3}$ a second $\mathrm{Ar}^{+}$ laoer tuned to the $457.9 \mathrm{~nm}$ line ionised the excited atom. Laser beams were propagated paraliel to and $\sim 2 \mathrm{~mm}$ above the sample filament, with ty pical beem diameters of $\sim 100 \mu \mathrm{m}$. A opherical murror was ineerted to retroreflect the laser beams collinearly. A magnetic sector mas apectrometer, equipped with pulse counting electronica, we used for detection of the lutetium ions. Samples were prepared by depositing $1.2 \mu \mathrm{g}$ of total lutetium onto a sonerefined rhenium filoment, along with a sumilar amount of tranium oxide to provide a diffusive barr.er. Spectre were taken at a flament temperalure of $\sim 1225^{\circ} \mathrm{C}$.

\section{RFSULTS AND DISCUSSION}

Saturation apectroncopy we discovered won after the advent of the firat gat laser. Bennet ${ }^{\circ}$ and Lamb' recopnised that the narrow resonances (Lamb dipa) that appeared in the center of inhomogeneoualy broadened gain profiles interacting with counterpropagating laser beams resulted from "holes" burned into the Marwell-Boltemenn velocity distribution.

T'reuent addrens: Naval llesearch Laboratory, Washington, DC 20375 
This phenomenon simultaneously provides a means for determining the center frequency of a transition and for removing the inhomogeneous line broadening.

Much saturation spectroscopy has been performed in a pump-probe scheme using a relatively high pressure static cell, with inherent difficulty in examining rare icotopes. In contrast, for the present experiments, the pump and probe are the same laser, and a low-pressire mass spectrometer is used as the detector. This removes possible pressure broadening effects and permits simple isotopically selective saturation spectroscopy of unenriched samples. Two features generally are observed: (1) dips which reflect line centers approaching their natural linewidth, and (2) crossover peaks which occur at the mean frequency of two hyperfine lines whose Doppler profles overlap. The details of the exact processes occurring in these experiments will be discussed more fully in a forthcoming paper.

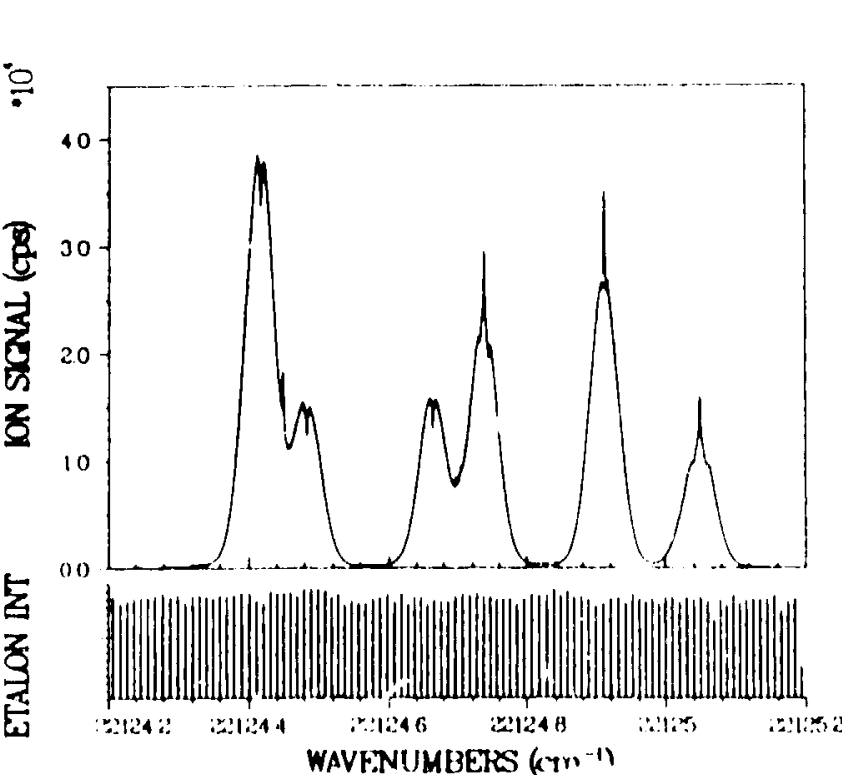

A typical experimental spectrom for ${ }^{175}$ / d s is shown in Figure 1. The dye and $\mathrm{Ar}^{+}$powers were $\sim 40 \mathrm{~W} / \mathrm{cm}^{2}$ and $\sim 8.5 \mathrm{~kW} / \mathrm{cm}^{2}$, 1 espectively. Similar ${ }^{176} \mathrm{Lu}$ spectira were al:10 observed but. are not shown. The dips and peaks correspond to the line centers and crossovers for the atonic HF components for lutetium (see reference 8 for details). Excellent signaito-noise $(S / N)$ was observed for both ${ }^{175} \mathrm{Lu}$ and ${ }^{176} \mathrm{Lu}$ spectra. Figure $L$ is an unsmonthed, expanded view of the first two bands in the ${ }^{173} \mathrm{Lu}$ spectrum and illustrates the $S / N$ and resolution attained using this technique.

Figure 1. Saturation spectrum of $(5 d \theta B \theta p$

${ }^{2} \mathrm{D}^{0}{ }_{3 / 2}+5 \mathrm{~d} \theta_{0^{2}}{ }^{2} \mathrm{D}_{3 / 2}$ ) transition of ${ }^{1 \% 3} \mathrm{~L}, 11$ at $\sim 22125 \mathrm{~cm}^{-1}$.

Included in the spectra, Figures 1 and 2 , are the transmission peaks of is $\sim 300 \mathrm{MHz}$ confocal etalon used for frequency calibratici. Fin increased prerision, the free spectral range of the stalon was determined to beter tian $2 \mathrm{ppm}$ using the Los Alamos National l,aboratory Fourier Transform Spactroneter (LANL FTS), greatly exceeding data requiremente. Because of this precision and the near natural linewidth characterizing the dipe and peaks, the hyperfine splicting constants for the ${ }^{175} \mathrm{Lu}$ excited states determined from the dip epectra (see Figures 1 and 2 ) are expected to be $\sim 5$ imes more precise than previously determined. 0.10 The exact decermination of the HFS conatants and their precision is presently underwny and will be presented in detail in reference 8 .

With a aimple experimental modification, i.e., the inclusion of "vibrating" mirror, removal of the Doppler pedeatal is possible. Earlier jtudien in a deandard gas ceil" have shown that this can be accomplished by modulating the mirrir and phrse detecting the innisation aignal. 


\section{CONCLUSIONS}

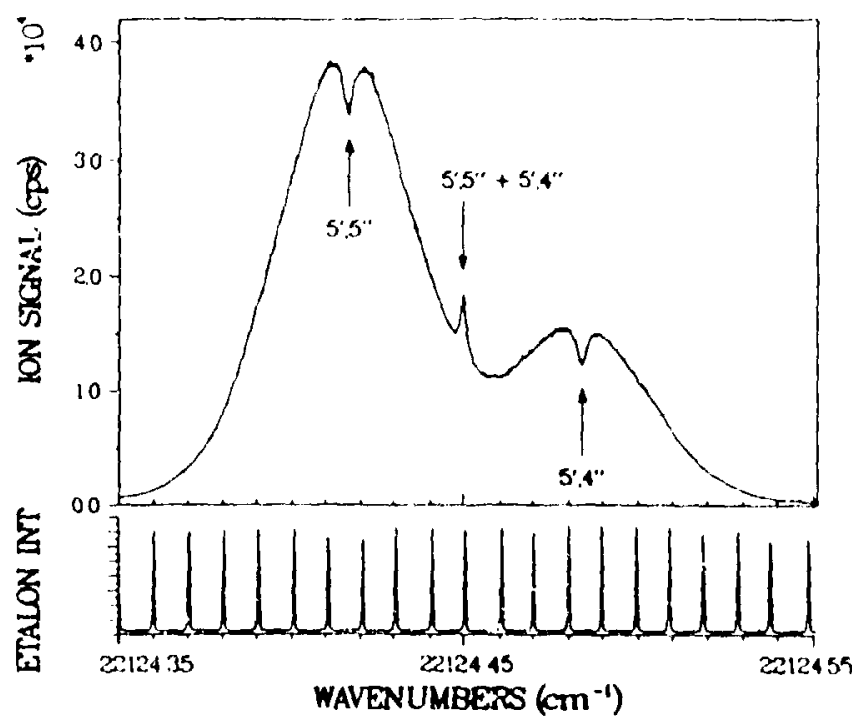

A new technique utilizing RIMS for obtaining very high resolution atomic spectra with isotopic sclectivity was demonstrated. This technique allows the precise determination of $\mathrm{HF}$ splitting constants, limited only by the transition's natural linewidth. In addition, it is also feasible with this technique to accurately determine atomic isotope shifts. The exact determination of HF component line positions provides data for isotopically selective ionization which, in turn, will increase RIMS' dynamic rarge. Future work includes the incorporation of a "vibrating" mirror and the study of rarer isotopes, i.e., ${ }^{174} \mathrm{Lu},{ }^{173} \mathrm{Lu},{ }^{172} \mathrm{Lu},{ }^{171} \mathrm{Lu}$, and possibly, ${ }^{170} \mathrm{Lu}$.

Figure 2. Expanded, unsmoothed spectrum of first iwo bands of ${ }^{173} \mathrm{Lu}$ shown in Figure 1 . The arrows point out the dips and crossover for the indicated hyperfine transitions.

\section{LITERATURE CITED}

1. C. M. Miller, N. S. Nogar, E. C. Apel, and S. W. Downey, in: Resonance lonisation Spectroscopy 1986, G. S. Hurst, and C. G. Morgan eds. (Inst. of Physics, Bristol, England), 109 (1986).

2. L. J. Moore, J. D. Fasseit, and J. C. Travis, Anal. Chem., 56, 2770 (1984).

3. N. S. Nogar, S. W. Downcy, and C. M. Miller, in: Resonance Ionization Spectroscopy 1964, G. S. Hurat, and M. G. Payne eds. (Inst. of P! ysics, Bristol, England), 91 (1984).

4. D. C. Parent, B. L. Fearey, C. M. Miller, and R. A. Keller, in: $35^{\text {th }}$ ASMS Conference Proceedings, 1006 (1987).

5. D. C. Parent, B. L. Fearey, R. A. Keller, and C. M. Miller, J. Opt. Soc. Am. B, (in preparation) (1987).

8. W. R Bennet, Jr., Phys Rev., 126, 580 (1962).

7. W. E. Lamb, Phys. Rev., 134A, 1429 (1964).

8. B. L. Fearey, D. C. Parent, R. A. Keller, and C. M. Miller, Chem. Phys. Lett., (in preparation) (1987).

9. R. Engleman, Jr., R. A. Keller, and C. M. Miller, J. Opt. Soc. Am. B, 2, 897 (1985).

10. C. M. Miller, R. Engleman, Jr., and R. A. Keller, J. Opt. Soc. Am. B, 2, 1503 (1985).

11. T. P. Duffy, D. Kammen, A. L. Schawlow, S. Svanberg, H. R. Xia, G. G. Xiao, and G.-Y. Yan, Opt. Lett., 10, 397 (1985).

\section{SUPPORT}

B.L.F. thanke Loe Alamo National Laboratory for postdoctoral fellowship support during the performance of this work. This research was supported by the U.S. Department of Finerxy under contract W-7405-FNG-36. 